International Journal of Engineering \& Technology, $7(1.4)(2018) 27-32$
International Journal of Engineering \& Technology
SPC
Website: www.sciencepubco.com/index.php/IJET
Research paper

\title{
The methodology of inheriting the traditional townscape by "Re-use" the heritage buildings -Through sharing the case studies in Japan and India -
}

\author{
Takashi Ono \\ Professor, Chitkara School of Planning and Architecture, Chitkara University \\ Email: takashi.ono@chitkara.edu.in
}

\begin{abstract}
This paper is to share the experience in case studies of Japan and India through focusing on the succession of the townscape based on the architectural 're-use'. It has tended in Japan in recent years in order to solve the serious issue of the vacant residences in rural area.

To begin with, based on the historian Kato's idea, the architectural manner divides three things; re-use, re-development and restoration/conservation. He insists that the architectural manner and the value of re-use were replaced by two concept of "redevelopment" or "preservation" that suddenly appeared in modern but still effective.

The researching place is selected following three cities; Obuse Town and Azumino City in Japan and Shimla in India. In case of Obuse, we made full use of existing properties of the town by re-using the space which has abandoned so far. And in case of Azumino, we can introduce the re-using building by changing the usage while utilizing the feature of the traditional houses.

This paper just introduces the present situation of the architectural re-use of Shimla because we are going on the survey on the site, and the concrete analyzing will be discussed in the next paper.
\end{abstract}

Keywords: Re-use, Townscape, Heritage building, Conservation, Restore

\section{Introduction}

This paper is to share the experience in case studies of Japan and India through focusing on the succession of the townscape based on the architectural 're-use'.

To begin with, even though the idea of "re-use" is not new, it has tended in Japan in recent years in order to solve the serious issue of the vacant residences in rural area. There are large numbers of vacant houses which resulted from the population decline as well as the urban concentration. Especially in Japan, it becomes a crucial theme that the fixed mindset of the new-built house, that is, the idea that something new is better than something old has to get out because of the mindset just brought by modernization. The theme should be discussed with not only Japan but also India.

Also, the idea 'Living heritage' which keeps the heritage buildings while living by adaptable re-using them, spreads out all over the world. This paper has discussed the succession of the townscape by the architectural re-use including the idea "living heritage". The methodology of this paper will be discussed as following. First, the architectural manner divides three things; re-use, redevelopment and restoration/conservation, then the idea of re-use can be defined clearly. Second, we discuss the way how the architectural re-use carried out in particular area. Through these discussions, the concrete example experienced by the author in Japan and India will share.

The researching place is selected three cities; Obuse Town and Azumino City in Japan and Shimla in India. Two cities selected in Japan were researched when the author was a vice-director of the Obuse Machizukuri Institute which is the first institute established jointly by the government and the university. In Shimla, India, collaboration project is going on with Yamana Laboratory, Tokyo University of Science. So, this paper only introduces the present situation of the architectural re-use and the concrete analyzing will be discussed in the next paper because of limited sheets of this paper. The focusing point is to discuss and share the idea, re-use, based on discussion of this paper as one of the architectural manner.

\section{The concept and methodology of re-use}

As per Architectural Historian, Prof. Koichi Kato, the manner of

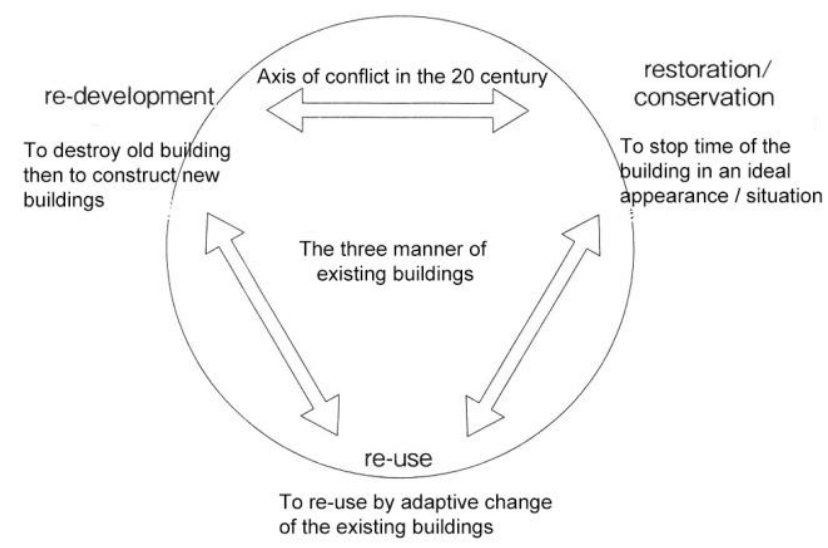

Fig.1: The Three manner of existing buildings (Source: Reference [3], P. 8) 
the existing buildings can divide three; re-development, restoration/conservation, re-use. Each technical term defines as follow;

"Re-development" $\cdots$ to destroy existing building, then to construct new building

"Restoration / conservation $\cdot \cdots$ to stop the time of the building in an ideal appearance / situation

"Re-use" . - to re-use by adaptive changes of the existing buildings

In addition, he clearly mentioned regarding historical relationship among three aspects.

"In the period of overwhelming growth from the 19th century to the 20th century, the time was "re-development" as a way toward existing buildings. ...... The approach of the "re-development" has embodied the spirit of "modern" seeking further development and further growth. This phenomenon, nevertheless to say, caused by economic principal. In opposition to such economic principle supremacy, "restoration / conservation" tried to remain historical buildings from the situation of re-development. The historical buildings appealed the "value" of them by using the metaphors of economic terms that historical buildings possessed "heritage" inherited from ancestral generations of human beings " [3].

Moreover, the restoration / conservation which Kato stated is the totally difference with the re-use because the basis of the idea, "restoration / conservation", never changes the appearance of the historical buildings to order to keep the original.

Prof. Kato insists that the concept of "re-development" or "preservation" actually appeared in modern times, but the concept of "re-use" goes back to the ancient days. Therefore, as mentioned at the beginning, the architectural manner and value of re-use were replaced by two concepts of "re-development" or "preservation" that suddenly appeared in modern. In other words, the once idea before modernization has paid homage to existing buildings, made changes according and maintained the building.

In Modernism after the 19th century, this value was lost, and architect has expressed new ideas on the vacant site just as God had imagined newly. In particular, this trend was remarkable in Japan. However, in Japan, the idea of re-use is gaining attention from old methods to new one again.

So, what procedure should be taken for the buildings as a method of re-use. Based on the own experience, the author supposes the followings;

1) Research findings

2) Documentation \& Identification

3) The manner of re-use

In addition, the understanding of not only the owner but also the townspeople becomes necessary for implementation. Hence, the re-using buildings in the town belong to the heritage of the town.

Focusing on each thing, first, research finding is basically necessary with the knowledge and the experience of experts. They must deeply understand the building and find value if someone sees nothing at first glance. In case of re-using, the treatment has a variety of ways, for example leaving and remaining all exterior or changing all things except a part of building. We must require what to do. At that time, we can easily touch a lot of information from international research organization such as INTACH and DOCOMOMO which has already many experts and experiences. Documentation \& identification is to document the building. Regardless of whether good or bad of building condition, through exactly recording the present situation by the drawing and writeups and photographs, it is possible to clarify its value to being back to the past and to help restore the building in the future. In order to promote this movement in the future, the proper documentation is required, so it is must to train the many experts for the future.

The other point is, in case of restoration, the question of whether it is meaningful to completely restore the former building. As discussed in the Madrid Document of declared by ICOMOS [2], adaptive re-use according to the current life style should be appropriate while inheriting the authenticity and integrity of the building. In that sense, we should grasp the current building and its detail exactly through reconfirming its value and set the criteria for re-use.

The manner of re-use will be discussed in details in next chapter.

\section{Case studies through the own field research survey in particular area}

\subsection{Obuse town in Japan}

\subsubsection{Obuse town and the Obuse Machizukuri Institute}

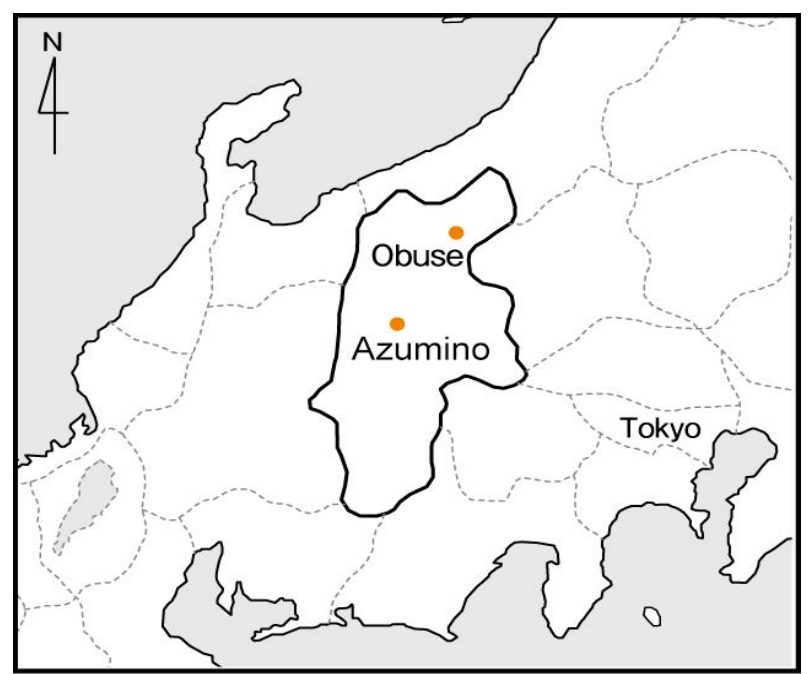

Fig.2: Map of Obuse Town and Azumino City (Source: Author)

Obuse Town is located in Nagano Prefecture, $250 \mathrm{~km}$ away from Tokyo (Fig.2). Roughly four kilometers square with a population of about 10,000, the town of Obuse has a well-developed central townscape surrounded by peaceful countryside and rich natural scenery. Although it used to be a rural area once in everywhere, more than one million tourists visit there a year in present since urban renovation has took place before 40 years. There are many reports regarding the details of urban renovation of Obuse Town so that everyone can access them. Overview of the project was to re-compose existing buildings, occasionally move them and carefully organize landscape and townscape.

The Obuse Machizukuri Institute was founded in collaboration with Obuse Town and the Tokyo University of Science as a specialized research Institution in order to build an academic foundation for the town and to devise the growth strategy. It aimed to review the town from an academic point of view, and to help revitalize the town [4].

\subsubsection{Finding components of townscape and its process of re-} use

Indeed, although the area in which the urban renovation was carried out certainly built the proper townscape of the central town it seemed there is nothing special such as the heritage building outside of the renovated area and outskirts of the town.

To begin with, what they have done is that the Obuse Machizukuri Institute had surveyed the existing buildings one by one within $4 \mathrm{~km}$ square of the town then identified the material and color of the roof as well as wall, and the design of the buildings and generated a variety of analyzing regional maps based on the survey. They have prepared analyzing regional maps which exhibited (Fig. 3).

Through the analyzing maps, there were large number of buildings which belong to silkworm houses, especially which has the shape of the pitched roof and hipped roof (Fig. 4). Thereby, it was identified that the roof shape which greatly affects the scenery of the town has its origin more than 200 years ago when the sericulture industry was popular in the town. 


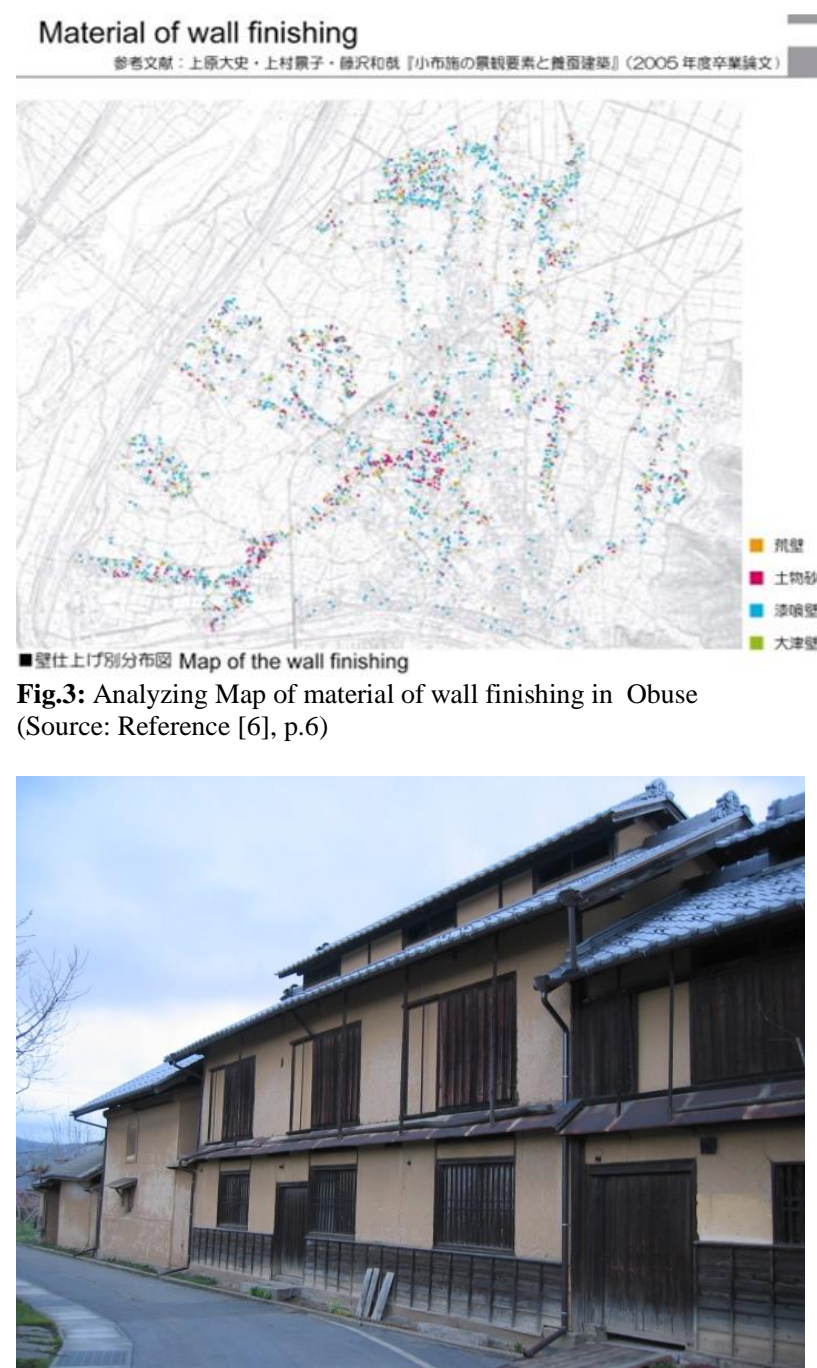

Fig.4: Exterior of the Silkworm house in Obuse (Source: Author)

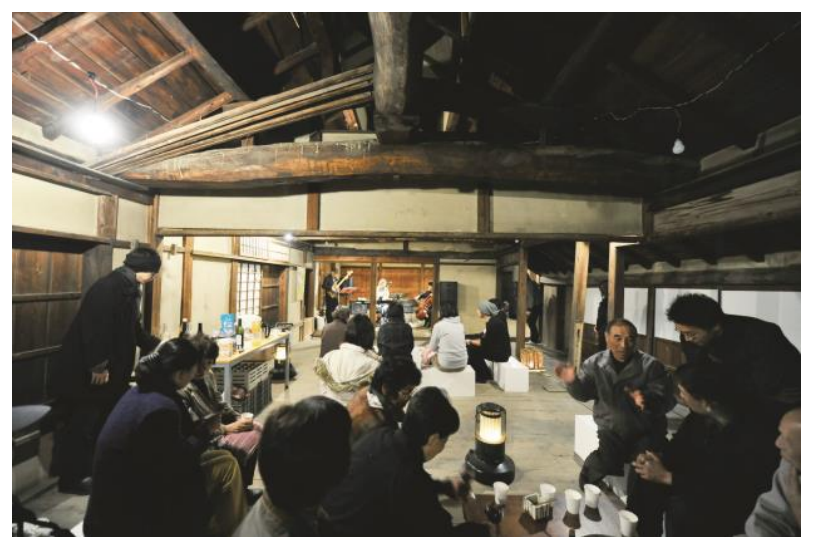

Fig.5: Re-using the interior of the silkworm house to temporary music hall for townspeople

(Source: Reference [4], p.52)

Needless to say, a variety of the houses have been built for 200 hundred years. Observing the situation of the houses inheriting the characteristic of the silkworm houses, these houses have already been vacant or not being utilized because of abandoning the profession for the sericulture industry. Although the space required to breed silkworms is spacious and proper thermal environment, the space becomes a store only [7].

Then, what they could do is to clean the space and open a temporary gathering space for townspeople (Fig. 5). Even though this project is not costly, it needed a lot of effort and time of participants and understanding of the space which has abandoned so far.

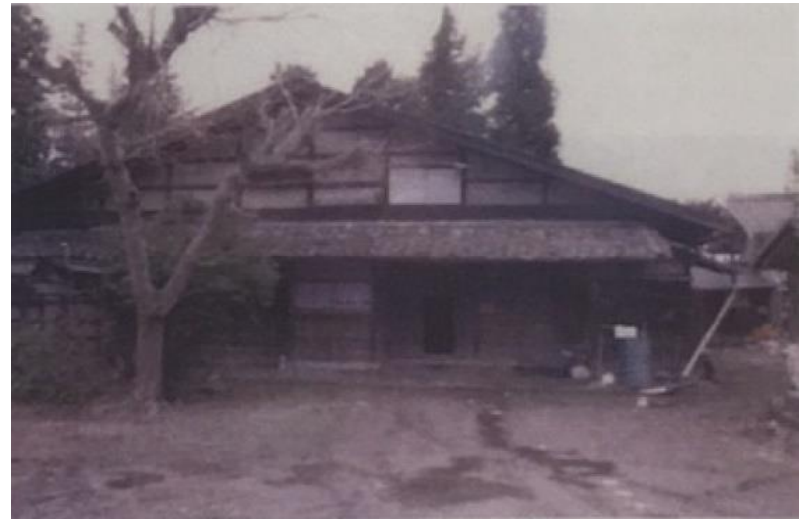

Fig.6: Exterior of Hon-mune-zukuri style house, Nadeshiko, before restoration (Source: Reference [1], p.27 and 40)

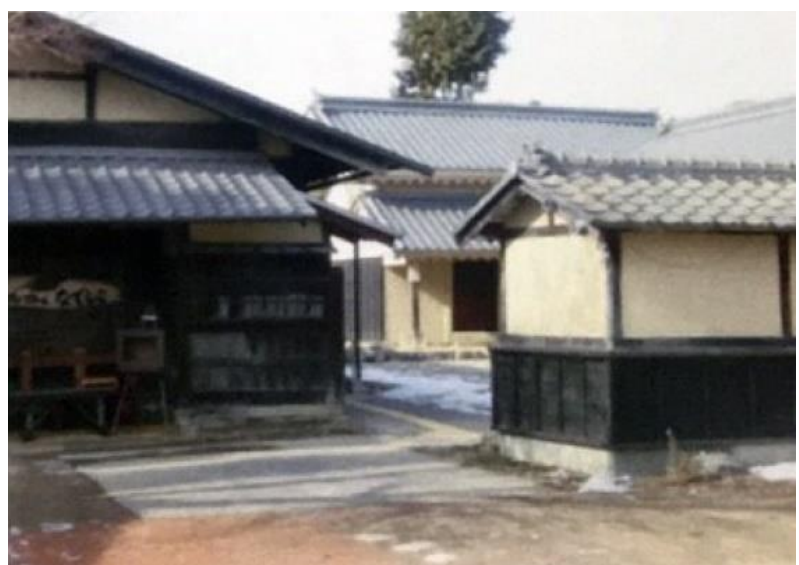

Fig.7: Exterior of Hon-mune-zukuri style house, Nadeshiko, in presen situation (Source: Reference [1], p.27 and 40)

\subsection{Azumino city in Japan}

\subsubsection{Outline of the city and traditional residence}

Azumino City is located in Nagano prefecture, about $250 \mathrm{~km}$ away from Tokyo (Fig. 2). There are many traditional houses that appeared around the 17th century and called the "Hon-mune Zukuri" style. These traditional residences have composed the townscape of the town. We can easily access precedence studies regarding this style [5]. The "Hon-mune Zukuri" style houses that built for a local lord and privileged merchants were extremely broad in comparison in current residence and are very difficult for descendants to maintain and manage them. As for the Azumino area, there are already many of their houses which lost their landlords and are not utilized as a vacant house.

\subsubsection{Re- using traditional houses by changing the usage}

Recently, those vacant houses have put the Residential Care Facility for the elders to practical use. In rural as well as urban area, the elder people live alone so that the facilities provide the living environment for them in peaceful and calm area in these days. Needless to say, it costs less than a new building. Considering the characteristic of Hon-Mune-Zukuri style house, it would be suitable building as a group home for the elders. The example is a Group home, which is called "Nadeshiko" in rural area in Azumino. Mr. Akinari Funakoshi, one of the members of the Obuse Machizukuri Institute, compiled as the Master Thesis [1].

A group home is a nursing home where elderly people gather and live. The merit of this building is to gather here and spend the rest of his/her life with everyone so that the elders will not be alone.

This facility mainly consists of 2 types of room; small private rooms are located at the perimeter of the building and a common living room for users is located at the center of this building. Also, 


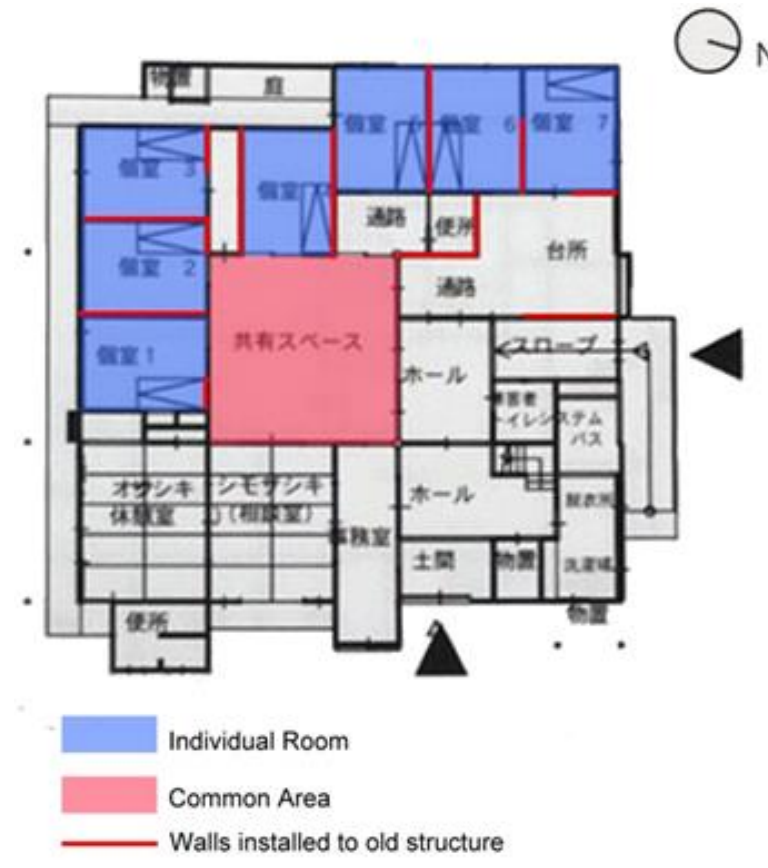

Fig.8: Planning of the group home "Nadeshiko" (Source: Reference [1], p.27 and 40)

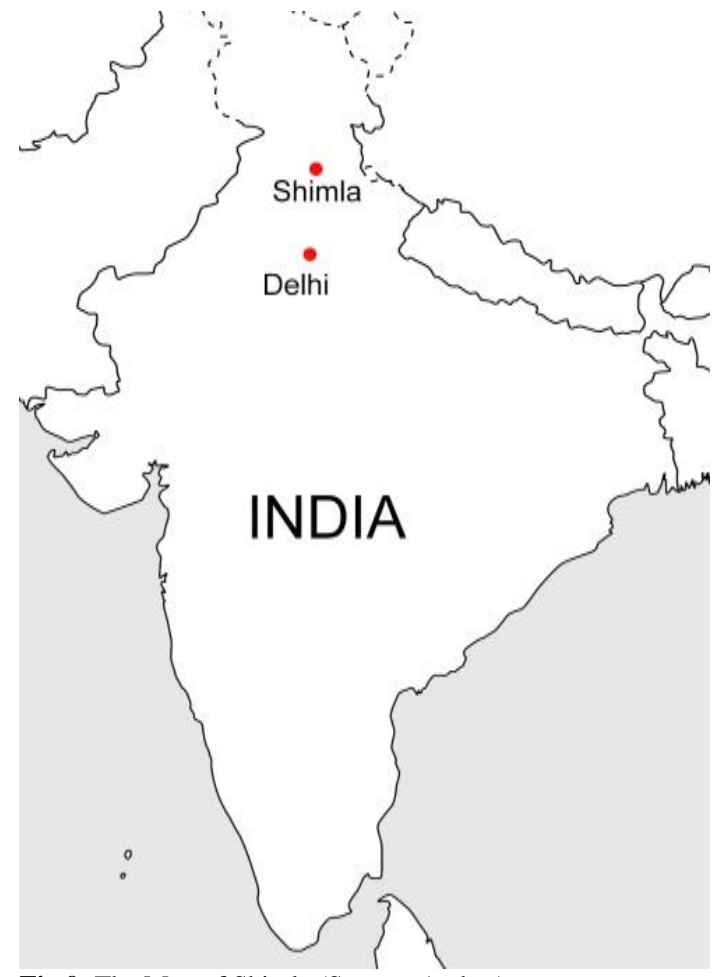

Fig.9: The Map of Shimla (Source: Author)

a large common bathroom was installed for users as well as disabled people. Several staff always stays 24 hours a day and care for them, for example, looking after meal, taking a bath and so on In the daytime, they can go out with elders and walk a peaceful countryside.

Even though it is not a large number of people, it costs a lot of money to set up this facility for the elderly. However, it is an elaborate remedy for not only elders but also traditional house to utilize the traditional buildings which compose the townscape through renovating the living environment according to their suitable present lifestyle. Therefore, re-using the traditional buildings can remain the traditional townscape which consists of them.

In addition, there are several ways, for example, re-using the traditional building as an accommodation for traveler etc., thereby remaining the one traditional townscape all over the Japan.

\subsection{Shimla in India}

\subsubsection{Outline of the City}

As well-known, Shimla is a Hill station in Himachal Pradesh, 100 km away from Chandigarh (Fig. 9). In 1864, as a summer capital during the colonial era, the town was constructed by the British, and even now it still has remnants of the British in those days. Since last year, an author has carried on a joint project with Yamana Laboratory, the Tokyo University of Science in Japan, and the purpose of this project is to learn how to remain the heritage town while inheriting the heritage building. As we have already completed the basic survey, we are planning to consider the specific heritage building. For research results, Mr.Yumino, a member of Yamana Laboratory, compiled as the Bachelor thesis [8].

\subsubsection{Treatment of the heritage buildings of Shimla}

According to the City Development Plan (CDP) authorized by Indian government, the existing traditional buildings and townscape define as the heritage, and conserve them while urban development for the city. The CDP mentioned 97 architectural heritage buildings as a target of conservation. Indeed, the scenery of Shimla's townscape makes us feel the face of Shimla which once belonged to the British. Its scenery had been remained by slightly restoring the then buildings, even though the building was not original completely.

As per the discussion with Mr. Tikender Singh Panwar, the Deputy Mayer of the Municipal Corporation of Shimla, "we do hope to take advantage of many heritage buildings as well as succeed the traditional heritage buildings to the future. But, the interest of the citizen of Shimla is still developing. As a purpose to increasing the interest for the heritage buildings, Heritage Walk started 2 years ago, that is, in 2014. Through such activities, it seems that the renovation is going on for public buildings, but it is difficult to preserve and renovate private houses."(Date and Venue: 17th June 2016 at the Municipal Corporation of Shimla)

In terms of the status of building renovation and re-use, Himachal Pradesh Public Works Department (HPPWD) at U.S. Club, Shimla, made the renovation plan and renovated such as Gaiety Theater, Town hall etc. According to the survey, those building which HPPWD renovated were resorted as close to original. The buildings selected by CDP, especially around the Mall road, are going to renovate.

Focusing the re-used buildings, 97 properties selected by CDP, there are many cases which change the usage of the past to another usage. For example, once residence for the British known as the Casplee School was used as a school in 1973 and as a heritage hotel in 1976. The interiors, including furniture, fabric, wall-paper, curtain, painting etc. remained unchanged since 1940. As another example, in those days the building which was a part of U.S. Club has re-used as the Chalet School with a small church on the top (Fig. 10 and 11).

Moreover, there are many heritage buildings not selected by CDP, and these buildings also has re-used. For example, the once chapel has re-used as a library of university. Indeed, the chapel which has large space may suit for library as a space which keeps huge number of the books (Fig. 12). In reality, there are same types of re-used buildings in the downtown of Shimla as the example of reuse.

Is it necessary to document these building in spite of re-using already? As mentioned the purpose and the role in Chapter 2, we have to understand historical buildings as a heritage of the town, accumulate them, so achieve to increasing the value of the city. In addition, townspeople can eventually get an important document that records the history of the town through recording the history developed as the British Colonial by an academic approach. 


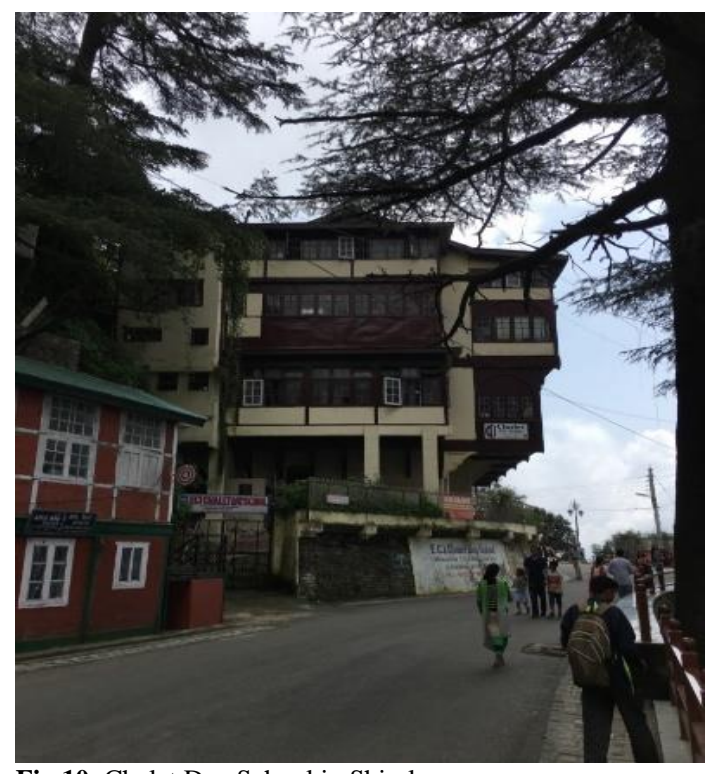

Fig.10: Chalet Day School in Shimla

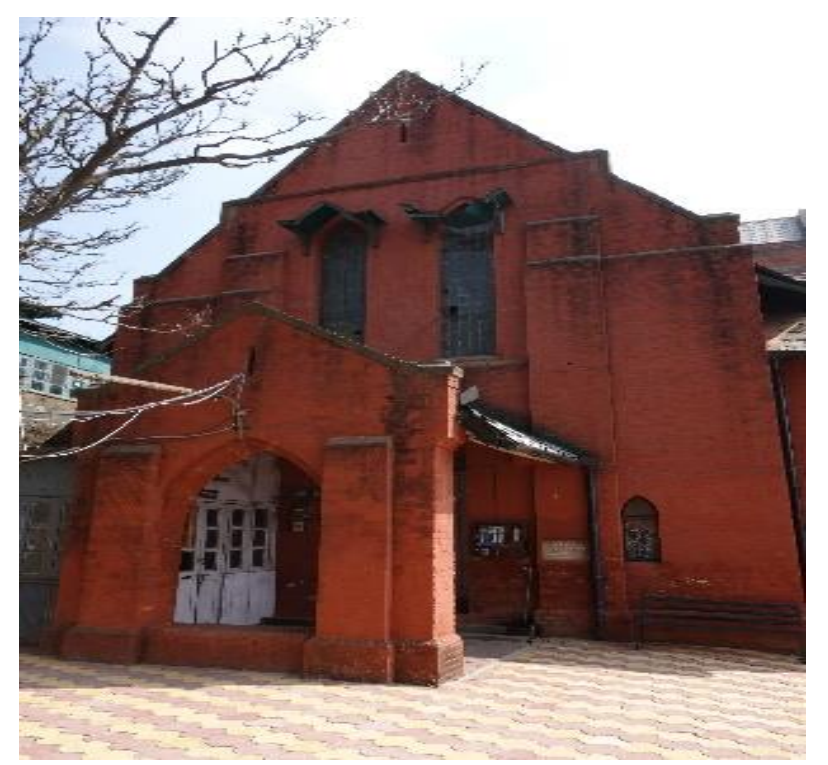

Fig.12: Left: Exterior of the library which was church

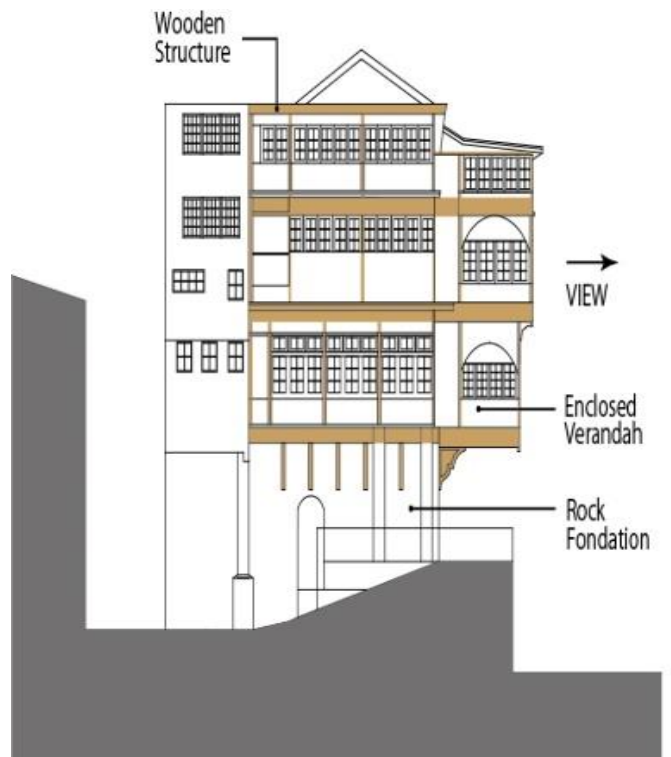

Fig11: Section of the Chalet Day School in Shimla (Source: Author)

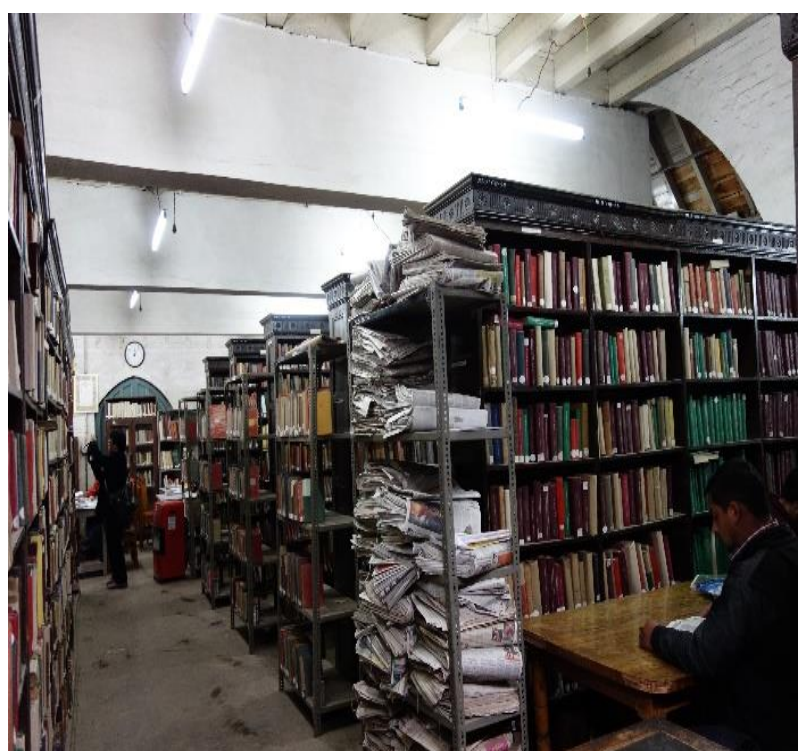

Source: Author)

\section{Conclusion}

Heritage Building which is one of the components composing the townscape has a variety of types. Not only the single building but also the group form which consist of several buildings has a big impact to the townscape. While re-using the Heritage buildings, an author focuses how to succeed the townscape to the future.

To begin with, according to the definition of the idea "re-use" by Professor Kato, re-use is completely difference with the idea "redevelopment" and "restore and conservation", and the architectural way "re-use" has effectiveness beyond the history. The procedure of re-use is three steps; 1)Research findings 2) Documentation \& Identification 3)Adaptive re-use and conversion. Three case studies which were shared on this paper are in Japan and India. Thereby, even though the situation of the respective area is pretty different, they have inherited traditional buildings and re-use them then remained the townscape.

The scenery of Obuse is the result of steadily taking part in the project for around 40 years since 1976. Although there were not many buildings that could be identified as Heritage Building, the project began observe all buildings carefully and find the value as a heritage of the town. Then, they carefully re-composed them to build a good living environment. Even in the case of Azumino, reusing the traditional building introduced the good result for a customer and for the towns, while it re-used well the traditional houses. There are so many options to re-oraganizing the usage for the traditional buildings, but first of all, we have to understand the characteristic and feature of the buildings exactly as a documentation stage.

In case of Shimla, through the interview and survey, we grasped various things. They understood the value of heritage buildings and began to remain and re-use positively. Fortunately still remaining heritage building showcases some re-use methods. So the author will share the research results to all on the next opportunity.

\section{References}

[1] A. Funakoshi, Master's Thesis: "Study on the reuse of traditional vacant residences in the rural area in Azumino City", Tokyo: Tokyo University of Science, 2012 [in Japanese].

[2] ICOMOS International Scientific Committee on 20th Century Heritage, "Madrid document: approaches for the conservation of twenth-century architectural heritage", 2011. 
[3] K. Kato, Architecture in Time: Survival of buildings through history and social change, Tokyo: University of Tokyo Press, 2017, pp. 15-64 [in Japanese].

[4] M. Kawamukai and the Obuse Machizukuri Institute, A University in the Town, the Town as a University, Tokyo: Shoukoku-sya, 2014 [in Japanese].

[5] N. Nakao, "The coincidence of the distribution area of Honmune style minka and the territory of the Shinano Ogasawara Family", Journal of Architecture and Planning, vol.71, issue 603, pp.147-154, Architectural Institute of Japan, 2006 [in Japanese].

[6] Obuse Machizukuri Institute, Annual report 2005, Tokyo: Obuse Machizukuri Institute, 2005.

[7] T. Katsumata, Doctor's Thesis: "The studies on the mechanism and its elements of the modern silkworm houses based on the analyzation of sericultural books" , Tokyo: Tokyo University of Science, 2012 [in Japanese].

[8] Y. Yoshihiro, Bachelor's Thesis: "Study on the preservation of historial architecture in the hill station - Through the survey of the heritage building in Heritage zone of Shimla", Tokyo: Tokyo University of Science, 2016 [in Japanese]. 